\title{
A Brief Study of Reticence in ESL Class
}

\author{
Hui Li \\ Beijing University of Technology, Beijing, China \\ Email: eynix@sohu.com \\ Yuhui Liu \\ Beijing University of Technology, Beijing, China \\ Email: liuyuhui@bjut.edu.cn
}

\begin{abstract}
It is a common phenomenon that students in China, either English or Non-English majors, are resistant to participating in individual or group-based speaking activities. This paper claims that students who refuse to actively participate in their own learning are reticent. Reticence in class impedes student learning, teacher effectiveness and classmate benefits of learning from silent students' insights, observations, and experiences. This paper takes a brief analysis of causes, effects of reticence problem and then proposes possible resolution of it.
\end{abstract}

Index Terms - English learning, reticence, communicative approach

\section{INTRODUCTION}

It is a common phenomenon that students in China, either English or Non-English majors, are resistant to participating in individual or group-based speaking activities, and the atmosphere of English classes are always inactive. As a result, the teachers' efforts in improving teaching quality used to end up disappointing.

In all sorts of ways, teachers are trying to involve the students actively in designing their course and planning interactions which would meet the students' needs and reasons to be willing to speak English. Their aims are to increase students' motivation to talk about what and how they want to learn. Through more personal engagement with class activities, it is expected that both students' confidence and their ability to speak English will be improved.

\section{A. Definition of Reticence}

Reticence is a communication problem with cognitive, affective, and behavioral dimensions and is due to the belief that one is better off remaining silent than risking appearing foolish (Keaten \& Kelly 2000). Reticent individuals tend to avoid communication in social and public contexts, particularly novel situations that have the potential for negative evaluation. The publication of Gerald M. Phillips's first article on reticence in 1965 was groundbreaking in that it expanded scholarly interest in communication anxiety problems and launched a major new line of research.

In this paper, reticence will be discussed in a specific situation- English classroom. Thus, reticence here belongs to the category of foreign language anxiety, which stands for the feeling of uneasiness, worry, nervousness and apprehension experienced by non-native speakers when learning or using a second or foreign language. These feelings may stem from any second language context whether associated with the productive skills of speaking and writing, or the receptive skills of reading and listening.

Reticent individuals refer to those who view themselves as incompetent communicators, and measured against norms about appropriate levels of talkativeness in social situations. In their minds, reticence is typified by a set of faulty beliefs about communication, for example, good communicators speak spontaneously and one must be born with good communication skills. The adoption of this set of beliefs creates anxiety and feelings of helplessness. Reticent individuals fear negative evaluation and appear foolish, and they have to learn to associate anxiety with communication. Here in this paper, the individuals being analyzed are students in English classes.

\section{B. Reticence in Class}

Among all sorts of classroom phenomena, the most frustrating one is that students will not or cannot actively participate in group discussions. Students' reticence, withdrawal, or fear of interacting not only deprives of them sharing what they know, but also deprives the teacher and classmates of benefiting from it. Thus students' reticence has a vital influence in teaching and learning process and there is an individual, teacher and classmate obligation to reduce or eliminate such phenomena.

A student's reticence in class not only reveals that he/she is unwilling to talk in certain circumstances; it could also indicate any of the following symptoms:

(1) the student's apathy toward the topic at hand or to the learning process itself;

(2) the student who is not comprehending is overwhelmed, or is bored;

(3) the student is isolated from the learning community; 
(4) the student has not learned the value or strategies of engagement or he/she does not appreciate or believe in that value.

Besides, reticence is not exclusively a problem for individuals who refuse or are unable to respond to direct questions; those silent students deprive their classmates of opportunities to benefit from their knowledge, insights, and thinking, in that lots of learning stems from idea and perception sharing. Often, one's contributions stimulate more and better thinking from others; everyone in a classroom is responsible for pulling their own weight; all need to participate - by discussing and by listening to others. Therefore, the reticent problem deserves to be seriously studied and solutions are expected by all who are concerned with teaching and learning.

\section{Possible CAUSES AND EFFeCtS OF RETICENCE IN CLASS}

Whatever phenomenon it is, there must be a cause, and reticence is no exception. The causes and effects of reticence are to be presented and analyzed as follows.

\section{A. Possible Causes of Reticence in Class}

The possible causes of reticence in class are to be discussed from the following aspects --- general causes, causes for foreign language anxiety and specific causes of Chinese students.

1. General Causes

There could be several causes which lead to students' reticence in class. Generally speaking, Incapable of actively and equally participating in class discussions might result from:

(1) low self esteem - students who think of themselves as unworthy or unable to communicate successfully, so they tend to remain silent out of shame;

(2) fear of being ridiculed when they inappropriately or inaccurately respond;

(3) fear of success - this occurs when a student interacts successfully; they attributes their success to luck or accident and then is apprehensive for others expecting him/herself to continue excellent performance, which means to interact with similar or superior success in the future;

(4) cultural differences - various cultures forbid or strongly discourage individuals from speaking up in classroom settings; sometimes for the reason of deference towards teachers; elder students' behavior could also contribute to this phenomenon;

(5) "to avoid conflict - inexperienced, shy, or less competent communicators rely upon silence to avoid conflict scenarios. Such avoidance should normally be easily diagnosed by alert teachers; and this strategy needs to be confronted delicately with alternative strategies offered as substitutes for unwanted silence" (Verderber and Verderber, 1986)

(6) communication apprehension - a clinical fear of communicating with or in the presence of others. Communication apprehension is often called CA for short. It is a major problem in the elementary school level. According to research, at least $31 \%$ of elementary school students need help dealing with Communication Apprehension (Holbrook, 2008). This term is widely studied and written about in Communication Studies literature.

Although all aspects of using and learning a foreign language can cause anxiety, listening and speaking are regularly cited as the most anxiety-provoking foreign language activities.

2. Causes for Foreign Language Anxiety

As for the causes of Foreign Language Anxiety, they have been broadly divided into three main components; communication apprehension, test anxiety and fear of negative evaluation.

Specifically, communication apprehension is the anxiety experienced when speaking with or listening to other individuals. Test-anxiety is a form of performance anxiety associated with the fear of doing badly, or indeed failing altogether. Fear of negative evaluation is the anxiety associated with the learner's perception of how other onlookers, instructors, classmates or others may negatively view their language ability.

\section{Specific Causes for Chinese Students'Reticence}

In their article "A Chinese Conceptualisation of Willingness to Communicate in ESL", authors Wen and Clement attempt something of a cultural anthropology of Willingness to Communicate in Chinese students. They conclude that the reticence to verbally engage is rooted in "two aspects governing interpersonal relations: an other-directed self and a submissive way of learning." (p. 19)

The "other-directed self" is based on the idea that Chinese culture, like many other Asian cultures, values the collective over the individual. This value could be traced back to the founding values of Chinese culture - "only in the presence of the other, will the self be significant. In Confucius theory, the self did not exist as a single entity. Its existential reality is dialectically related to the family, the community, the nation and the world. Self is relational, and it is defined by the surrounding relations. In Chinese culture, the social and moral process of 'conducting oneself' is to be aware of one's relations with others. Chinese people can never separate themselves from obligation to others." (p. 20)

The value placed on relations to others defining the self relates closely to the concept of "face". Face is lost when one behaves badly in class. "It seems likely that Chinese students would be even more sensitive to the judgment of the public upon their language behaviors and, therefore, less likely to get involved in classroom communication." Not 
incidentally, Wen and Clement identify a cultural trait that places value on resisting "outsider culture," which may result in additional difficulty in adapting to different norms of verbal participation.

The second major factor detailed in this study is submission in learning - the tendency of Chinese teachers who used to play an authoritative role and of Chinese students who tend to submit to authority in the process of learning.

Submission in learning deeply shapes how Chinese students engage in ESL classroom. The teacher is seen as the source of all knowledge and input, so Chinese students will not value partner and small group work as highly as students of other cultures. In addition, another point should also be accounted - Chinese learners' enthusiasm for grammar, which is the "law" of the English language in their opinions. Thus, accuracy is valued much more than fluency and the lack of latter further diminish students' willingness to communicate.

\section{B. Effects of Reticence in Class}

The effects of reticence are particularly evident in ESL classes and it, to some degree, is a strong indicator of academic performance. Reticence is found to have a detrimental effect on students' confidence, self-esteem and level of participation.

Reticent learners suffer from mental blocks during spontaneous speaking activities, lack confidence, are less able to self-edit and identify language errors and are more likely to employ strategies such as skipping class. Anxious students also forget previously learned material, volunteer answers less frequently and have a greater tendency to remain passive in classroom activities than their less reticent counterparts.

The effects of reticence could also extend outside the second language classroom. A high level of reticence might also correspond with communication apprehension, causing individuals to be quieter and less willing to communicate in other public occasions. As a result, people who exhibit this kind of communication reticence are more likely to be perceived as less trustworthy, less competent, less socially and physically attractive, tenser, less composed and less dominant than their less reticent counterparts.

Therefore, working on reticence problem in and out of class is of great significance not only in academic development, but also in mental development of the students.

\section{RESOLUtion OF RETICENCE IN CLASS}

Since reticence poses vital influence on foreign language learning and teaching, a number of solutions have been studied by foreign language scholars in the attempt to resolve the problem, among which communicative language teaching (CLT) is the most-widely accepted one. However, adopting CLT solely might result in ignoring students' individual factors which contribute to reticence in classrooms; therefore, some additional methods also deserve to be carefully observed.

\section{A. Communicative Language Teaching Method}

\section{CLT's Features That Contribute to Solving Reticence Problem}

CLT is an approach to the teaching of second and foreign languages that emphasizes interaction as both the means and the ultimate goal of learning a language. It is also referred to as "communicative approach to the teaching of foreign languages" or simply the "communicative approach".

As an extension of the notional-functional syllabus, CLT also places great emphasis on helping students use the target language in a variety of contexts and places great emphasis on learning language functions. Its primary focus is on helping learners create meaning rather than helping them develop perfectly grammatical structures or acquire native-like pronunciation. This means that successfully learning a foreign language is assessed in terms of how well learners have developed their communicative competence, which can loosely be defined as their ability to apply knowledge of both formal and sociolinguistic aspects of a language with adequate proficiency to communicate. It is the communication that could break the silence in class and raise the motivation of talking.

CLT is usually characterized as a broad approach to teaching, rather than as a teaching method with a clearly defined set of classroom practices. Features of CLT could be concluded as: "(1) an emphasis on learning to communicate through interaction in the target language; (2) the introduction of authentic texts into the learning situation; (3) the provision of opportunities for learners to focus, not only on language but also on the Learning Management process; (4) an enhancement of the learner's own personal experiences as important contributing elements to classroom learning; (5) an attempt to link classroom language learning with language activities outside the classroom." (David Nunan's, 1991)

CLT might be the most effective way of creating opportunities for reticent students who are always inactive to seek for their own, for the reason that it puts emphasis on learning to communicate over memorize. Moreover, CLT stimulates students' interest in that it associates their personal experiences as important contributing elements to classroom learning.

\section{Class Activities and Procedures of CLT That Contribute to Solving Reticence Problem}

CLT's class activities and teaching procedure are also of great value in solving reticence problem.

Littlewood (1981) distinguishes between "functional communication activities" and "social interaction activities" as major activity types in CLT. Functional communication activities include such tasks as learners comparing sets of pictures and noting similarities and differences; working out a likely sequence of events in a set of pictures; discovering 
missing features in a map or picture; one learner communicating behind a screen to another learner and giving instructions on how to draw a picture or shape or how to complete a map; following directions; and solving problems from shared clues. Social interaction activities include conversation and discussion sessions, dialogues and role plays, simulations, skits, improvisations, and debates.

Both the two types of activities in CLT require all the students' participation, while functional communication activities emphasize more interaction and social interaction activities focus more on practicing oral English in communication. Therefore, the former one could be used as a warm-up method to forge an interactive atmosphere in class, which could make students relaxed and release the tension among reticent ones. When those who tend to be reticent get used to the environment, it is highly possible that they have formed their own notions during the activities, and it is high time for teachers to encourage conversation and discussion gradually.

3. Roles of Teachers and Students of CLT That Contribute to Solving Reticence Problem

The emphasis in communicative language teaching lies on the process of communication rather than the mastery of language forms; it leads to different learners' role from that found in traditional second language classroom. Breen and Candlin describe the learners' role of CLT in the following terms:

The role of learner as negotiator - between the self, the learning process and the object of learning - emerges from and interacts with the role of joint negotiator within the group and within the classroom procedures and activities which the group undertakes. The implication for the learner is that he should contribute as much as he gains, and thereby learn in an interdependent way. (1980:10)

Once the reticent student learns that he/she should not be only a good listener but also an active negotiator and he/she, like anyone else, is responsible for contribution in group activities, the individual might feel obliged to participate and fulfill his/her role as a second language learner. On occasion, such psychological implication might take inconsiderable effects in helping students to overcome reticence.

\section{B. Other Solutions for Solving Reticence Problem}

Except for the application of communicative approach, there are several other methods which concern more about students' psychological status and personality related factors.

For the students who have excessive shyness, the teacher might start with face-to-face communication or discussion in a relatively small group. Telling the benefits of dealing with shyness could also work. With attention and encouragement, most teachers can help reticent students tremendously.

For the students who choose to be reticent in class for the reason that they don't know how to ask a right question, critical thinking, creative thinking, or verbal skills need developing to adequately formulate effective questions. For illustration, teachers could encourage students to take different viewpoints or role play in order to practice asking questions and engaging in dialogue with a teacher. Thus, they could learn to question anything unclear to them and get used to the way of raising a question.

For those who remain reticent because of inadequate motivation, it is wise to analyze possible causes over a period of time. Some teachers use a point system to give students a concrete sense of progress. They give points for students who act positively in class. This method, especially in China where students seriously concern the points of a course, might be highly reinforcing and effective.

\section{CONCLUSION}

The reticence in classroom is the outcome of many structural and ideological factors that undermine students' potential for learning and for generating classroom debate; such unpleasant outcome is somewhat inevitable in teaching and learning process. However, the bad influence could be diminished through efforts by both teachers and students themselves. To find the general causes of reticence problem and then work on it through appropriate resolution can motivate and help the students to overcome it, thus changing the embarrassing classroom situation as well as improving students' learning ability.

\section{REFERENCES}

[1] Breen, M.P. \& Candlin, C. (1980). The Essentials of A Communicative Curriculum in Language Teaching. Applied Linguistics $1 / 2,89-112$.

[2] Holbrook, Hilary Taylor. (2008). Communication Apprehension: The Quiet Student in Your Classroom. ERIC Clearinghouse on Reading and Communication skills Urbana IL. November 2.

[3] Kathleen S. Verderber, Rudolph F. Verderber. (1986). Inter-Act. Wadsworth Pub Co.

[4] Keaten, J.A., Kelly, L. \& Finch, C. (2000). Effectiveness of The Penn State Program in Changing Beliefs Associated with Reticence. Communication Education 49, 134-145.

[5] Littlewood, W. (1981). Communicative Language Teaching. Cambridge: Cambridge University Press.

[6] Nunan, D. (1991). Language Teaching Methodology. New York: Prentice Hall.

[7] Wen, W. \& Clement, R. (2003). A Chinese Conceptualisation of Willingness to Communicate in ESL. Language, Culture and Curriculum 16, 18-38. 
Hui Li was born in Beijing, China in 1987. She received her B.A degree in English from Beijing University of Technology in 2009. She is currently a graduate student in College of Foreign Languages, Beijing University of Technology, Beijing, China. Her main interests include conversation analysis and language teaching.

Yuhui Liu is a professor in College of Foreign Languages, Beijing University of Technology, Beijing, China. She has published more than 30 academic papers on English teaching \& learning and on conversation analysis, and more than 20 textbooks and workbooks on vocabulary, listening, reading and writing as the first author or chief editor; she has been in charge of more than 10 academic research projects about teaching methodology, teaching reform, and conversational analysis \& teaching of listening and speaking. 